\title{
Erratum to: Lasers in Additive Manufacturing: A Review
}

Hyub Lee, Chin Huat Joel Lim, Mun Ji Low, Nicholas Tham, Vadakke Matham Murukeshan, and Young-Jin Kim

Published online: 12 July 2017

(c) 2017 by KSPE and Springer

Int. J. Precis. Eng. Manuf.,-Green Tech., Vol. 4, No. 3, pp. 307-322, 2017

DOI: $10.1007 / \mathbf{s} 40684-017-0037-7$

The figure 15 in page 315 should be modified as below:

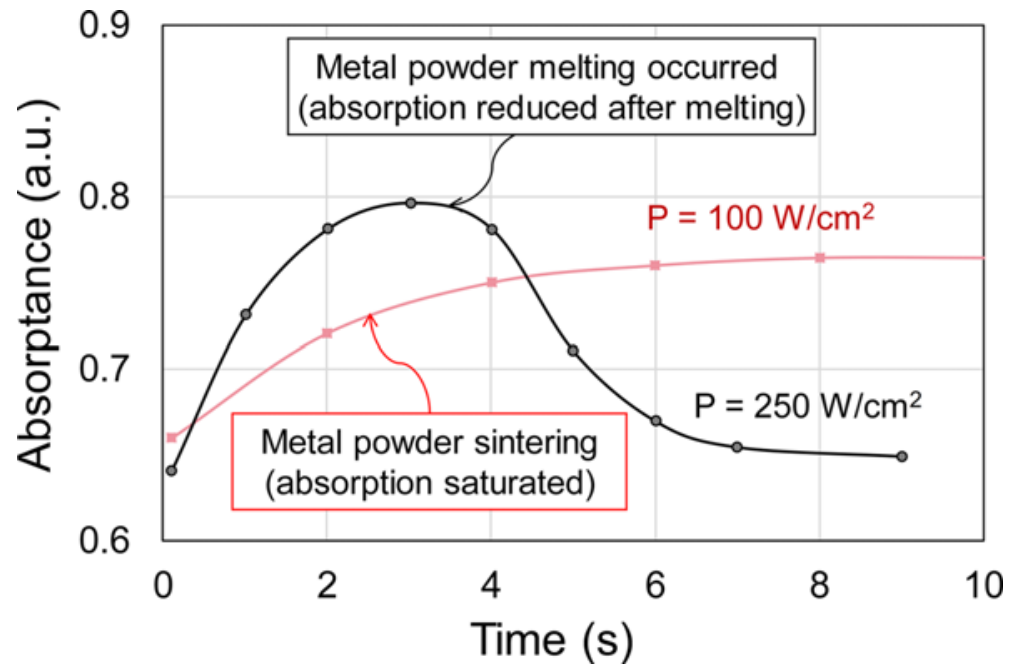

Fig. 15 Variation of absorption of Ni-alloy I metal powder with Nd:YAG laser processing time68

The online version of the original can be found under

DOI: $10.1007 / \mathrm{s} 40684-017-0037-7$

\#Corresponding Author: Young-Jin Kim

School of Mechanical and Aerospace Engineering, Nanyang Technological University, Nanyang, Singapore

E-mail: yj.kim@ntu.edu.sg 